\title{
A proposal to measure the impact of automated response systems on meeting student learning outcomes
}

\author{
Josiah Koh, Michael A Cowling, Meena Jha, Kwong Nui Sim \\ Central Queensland University, Central Queensland University, Central Queensland University, Auckland \\ University of Technology
}

\begin{abstract}
With the advancement of Artificial Intelligence (AI), much has been made of the use of AI in education. Central to that is the idea of an Automated Response System (ARS). Current adoption of ARS's in education has been mainly in the realm of administrative tasks but is likely to move into the support of teaching. ARS can be used as a supplement for teaching as it provides instant feedback, and 24/7 support. Having a highly accessible, 24/7 ARS can help relieve some of the burdens placed on teachers, especially in a post COVID-19 environment, where teachers expect work to intensify, rather than simplify. In this paper we present a work-in-progress that proposes what features an ARS for education should have, how these would be useful and how these features help teachers assist students meet their learning outcomes in a holistic manner.
\end{abstract}

Keywords: Automated Response Systems, Learning Outcomes, Higher Education

\section{Introduction}

One of the greatest issues facing higher education is the lack of experts and teachers (García \& Weiss, 2019; UNESCO, 2016) due to the rapidly increasing rate of knowledge generation and expansion of new knowledge horizons and areas of expertise (Holmqvist, 2019). The COVID-19 pandemic has further exacerbated this problem by shifting most of the learning online, where many teachers who have traditionally taught in a face-toface environment have struggled to adapt to the new medium of delivery (Diliberti \& Kaufman, 2020). The increased time burdens placed on the teacher, on top of having to adapt content delivery and assessments to an online medium meant that the typical requirements of teaching were further compounded (Dhawan, 2020). This led to teachers facing higher levels of stress, somatic burdens and emotional exhaustion (Collie, 2021).

The advancement of AI has allowed the application, albeit limited, of AI in online learning environments to act as academic support (Maderer, 2016) Advancements in AI have potentially created new ways to teach and learn, and to monitor and support students (Atif et al., 2021). This has caused AI-enhanced teacher-robots (aka 'teacherbots') to gain traction (Fast \& Horvitz, 2017). Thus, there has been a heightened hope that AI can help alleviate some of this teacher burden by supplementing some of the tasks that are required from teachers (Edwards \& Cheok, 2018). However, typical ARS systems implemented in educational institutes operate too similarly to commercial chatbots, primarily following pre-determined question and answer pairs and directing more complex or unanswerable queries to human users.

This paper will look at how an ARS could be reframed to enhance these teacherbots and provide a framework for building this system with enhanced features compared to a traditional chatbot, answering the question What features should an ARS have, that would meet the learning outcomes of students in a course and to what extent are students' learning outcomes impacted by the implementation of an ARS?. It will finish with a research design for evaluating the success of this approach based on Design-Based Research (DBR). The rest of the paper is organised as follows: Section 2 discusses the background of the research, Section 3 provides the experimental design, and Section 3 provides conclusion and future work.

\section{Background}

As noted in the introduction, AI has been in use for online learning environments to act as a teaching aide or as an academic support, such as 'Jill' Watson, a knowledge based artificial intelligence (KBAI) virtual teaching assistant (Maderer, 2016) and VIRtual Teaching Assistant (VIRTA) (Jha et al., 2020), but limited mainly to functionality similar to that of a marketing-style chatbot (such as chatbots that recommend products to 
customers in commerce shopping sites). This more functional approach of Automated Response Systems (ARS) acts more as a directory and may not be useful in supplementing teachers in a more dynamic settings such as online learning environments. Central to the automated teacher are the ARS systems. ARS are pre-designated responses or replies that are generated by a software program for incoming queries and/or messages.

Commercially available ARS systems end to have a combination of features highlighted, such as personalised responses, instant feedback, high accessibility, 24/7 support and the ability to provide basic feedback (Jha et al., 2020; Microsoft, 2020; Pinkwart, 2016; Squirrel AI, 2019). In place of supporting purchasing and marketing, ARS can be implemented (especially in online learning environments) to support how students learn. ARS can provide instant feedback, and support collaboration and give administrative support to help students stay engaged, motivated and get more access to support 24/7.

The idea of 'teacherbots', which are teacher-robots that are enhanced with AI, are gaining traction (Fast \& Horvitz, 2017; Popenici \& Kerr, 2017). Squirrel AI has also claimed to be able to have an adaptive AI teacher that could improve student grades, particularly those in annual standardised tests, also known as gaokao (Hao, 2019). In the US particularly, AI enhanced learning systems have gained increasingly positive impressions (Fast \& Horvitz, 2017), with more recognition for systems such as ALEKS, Knewton and Dreambox Learning.

Proponents point to these systems as being a better way of teaching as these teacherbots promise hyperpersonalisation in learning (Hao, 2019), reduce administrative workloads (Popenici \& Kerr, 2017) and allow for different ways of engagement. With hyper-personalisation, one-to-one teaching could be conducted at scale. This will, in theory, directly solve the teacher's shortage problem, increase accessibility and provide learning directly catered for each student. Proponents will also point to AI's ability to improve student's academic grades (Wang et al., 2020), increase student engagement and satisfaction (Goel \& Joyner, 2015; Microsoft, 2020). Within this context, architecture-based frameworks have been suggested (Hou \& Fidopiastis, 2017; Tiina \& Ioana, 2016), which focuses on the user experience or the evaluative process or on systems itself. However, studies discussing conceptual or theoretical frameworks framed within pedagogical perspectives, specifically looking at the wholistic learning outcomes, are very few.

In addition, the common critique is that teacherbots are unable to understand and interpret emotional cues, and thus unable to 'teach'. Teaching is relational and much more nuanced (Siemens, 2020). AI has not reached to the level of development where it can pick up emotional cues and interpret these cues accurately (Stein, 2018). Thus, teacherbot relegates learning to a transactional activity about getting grades and certificates, as opposed to learning. Another common critique is that teacherbots will drive students to learn in silos. Interreacting with peers opens up new and important ways of learning, especially by way of reification (making sense of abstract information) and active participation (Wenger, 1998; Whiteside, 2015). Studying online is already an isolated experience (Liu et al., 2007), but having an AI teacher further reduces the need for social interaction.

\section{Community of Inquiry Model}

To better understand what features an ARS should have in an online learning environment, it could be useful to start by looking at one of the most used frameworks for understanding student educational experience in an online environment, the Community of Inquiry (CoI) model (Garrison et al., 1999). The CoI model provides a visual presentation of elements in a livelier and engaged online learning environment and has proven its success in its implementations across various online learning environments (Cooper \& Scriven, 2017). Consisting of the three main dimensions of social, cognitive, and teacher presence; the CoI model basically shows how the overlap of all three presences focussed themselves in creating conditions that explain the student learning experience.

Each dimension is complemented with a 4-phase model of practical inquiry, namely triggering event, exploration, integration, and resolution. As a guide, this would help show that the process of each feature should contribute to at least one of each of the phases for each of the dimensions. Current applications of using $\mathrm{CoI}$ in online learning has seen features such as talk channels, course content catered for online teaching and feedback channels (Rubin et al., 2013). Thus, it is a useful model for features that an ARS can consider than what is already typically available such as facilitating discussions or how to enhance existing features with automated responses so as to elevate the educational experiences to meet learning outcomes.

An ARS could also consider aspects of the educational experience such as motivation and engagement. Traditionally, teaching presence is thought to be more central to COI and influences both social and cognitive presence. Teacher presence tends to indicate a weaker correlation with the intrinsic motivation of a student (Cole et al., 2017; Koh, 2021). Higher levels of responsiveness communicates an increased teacher presence, 
which in turn leads to higher levels of engagement (Zhang \& Liu, 2019). This is also mirrored by claims from companies that their automated teachers have been able to produce a better student learning experience and a higher quality academic output. For instance, Squirrel AI has claimed that their algorithms have helped curate and personalise individualised learning for each student, providing better educational outcomes (Hao, 2019). The CoI model is criticised as systems centric and does not sufficiently take into account the importance of learners themselves to the effectiveness of learning (Cole et al., 2017; Shea \& Bidjerano, 2010). As teachers are not physically present, the onus of learning falls more on the student's shoulders. The CoI tends to look at the way that the online education can be conducted, then claims credit for learning successes without sufficiently acknowledging that students themselves (such as motivation) drive a huge part of that learning success.

Figure 1. Design Based Research Cycle

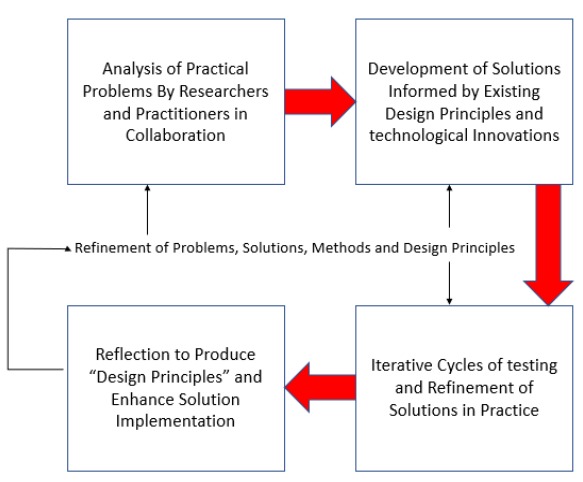

Figure 2. Potential Features of the ARS

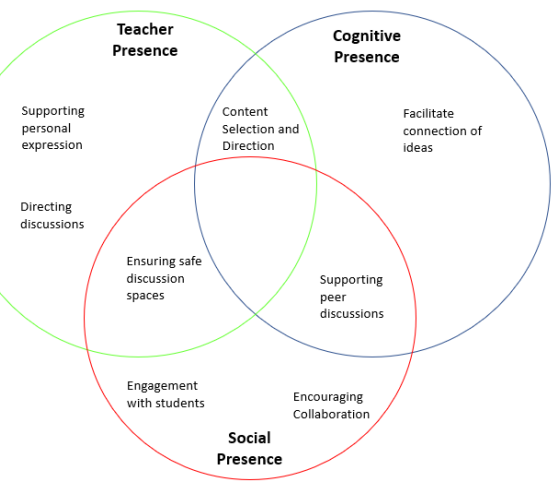

\section{Research Design}

To find out which features of an ARS would help students meet learning outcomes, a design-based research approach (DBR) will be undertaken (Reeves, 2006). This allows for the application of educational theories in an exploratory fashion for understanding "how, when, and why educational innovations work in practice" (Baumgartner et al., 2003; Reeves, 2006). But most importantly, it allows for multiple iterations which gives us the bandwidth to make the necessary adjustments before the next iteration. This will allow us to be able to make the necessary changes to move closer to answering the research questions.

As shown in Figure 1, the first phase requires the problem to be defined and the parameters identified. In this case, we want to know what features would be needed and if it has any impact on the learning outcomes. Currently, most learning outcomes look primarily at the idea of 'learning gains' (Guan et al., 2020; ZawackiRichter et al., 2019), measured through test scores or grades. However, what students learn are more than just grades. Social interaction, student engagement, student motivation, teaching experience, peer learning and learning environment on top of the learning gains should be viewed as parts of the wholistic learning outcomes that should be measured. As such, a mixed method approach to the data collection would be valuable (Ryu, 2020) as learning outcomes are a mix of learning gains, motivation, engagement and student experience.

In the next phase, we explore the development of a solution by first exploring what current ARS features are available. Previous mentioned ARS features tend to primarily focus on the teaching and/or cognitive presences of the CoI model (Underwood \& Luckin, 2011; Zawacki-Richter et al., 2019). For an ARS to better support teachers, especially post COVID-19, it would be helpful if the ARS also help facilitate some of the social learning and social cognitive aspects of education. Potential features when considering the CoI model is seen in Figure 2. These features are informed in part to the CoI model. To some extent, what is measured will shape how the ARS would be tweaked.

Finally, the third phase would involve iterative cycles of testing and refinement. An online higher education class/course is selected for our study. Students will have the option to opt into the study. They will be split into 2 groups, one using the ARS and one not using the ARS. The measurement tools will be deployed to have a baseline. After the ARS has been implemented and used, the measurement tools can be re-deployed to see if there are any significant differences between the two groups. Students from each group will be swapped after the mid-point of the term to ensure that no student will be disadvantaged. Data collected will be analysed and used to inform the next iteration if more features should be added or if features are not as effective. 


\section{Methodology}

In the first iteration, we want to see if the ARS has the necessary features that help meet learning outcomes. The current base level of learning outcomes will first be obtained via a series of both qualitative and quantitative means. A mixed method approach to the data collection would be deployed. Depending on the learning outcome to be measured, a different approach could be used. For student engagement, a mix of quantitative survey instruments such as the Online Student Engagement Scale (OSES) (Dixson, 2015) and qualitative semistructured interviews to give further depth to the quantified responses. Using the OSES would be relevant due to its nature of being focused on online students and its focus on participation and achievement. To supplement the OSES, the MOOC engagement scale (MES) (Deng et al., 2020) could be used as well to provide more context in the cognitive, behavioural emotional and social engagements. Peer learning and social interaction related learning outcomes can be measured using the National Survey of Student Engagement (NSSE) (NSSE, 2015). The NSSE is a good instrument for measuring student motivation and engagement with components that relate to the interaction between social and teaching presences as well. However, the NSSE could be further complemented with the University Student Engagement Inventory (USEI) (Maroco et al., 2016). The USEI has a more targeted focus on the academic learning and achievement in relation to learning with peers. These instruments are chosen for their validity, relevance and wide adoption. Opt-in semi-structured interviews would be conducted to give insights on whether the features were interpreted accurately, whether it was used as intended and their comments on student experience, engagement and social participation can provide more context to the survey data gathered earlier. These insights, especially post intervention, will allow for a better refinement and/or addition of new features to be used in the next iteration of the DBR cycle.

Thereafter, a current market ARS (such as Q-bot) would then be implemented. It would include the typical features of an ARS such as individualisation and instant response. Students' engagement with the ARS will be monitored and recorded via mouse clicks or time. At the end of the course, another evaluation of the learning outcomes to see if there has been any improvement in the meeting of them. A comparative analysis would be conducted to see if any of the features had made an impact on the students meeting the learning outcomes. Post analysis, tweaks will be made to the ARS before a second iteration will be commenced. Further iterations will continue until there seems to be no significant increase in the meeting of learning outcomes and we are thus satisfied that most of the features have been found.

\section{Conclusion and Future Work}

Current studies have shown the aspects of an ARS that are ideally expected are that of hyper personalisation and instantaneous feedback. There is also an expectation that there will be back-end analytics running in the background that alert the teachers of potential issues via predictions. An ARS that is framed within an educational perspective with an eye on learning outcomes will be useful as it will be more in line with helping to alleviate some of the teaching load, where teachers can build on the knowledge impartation of the ARS and add the relational and nuances of teaching. This paper has presented a framework for evaluating an ARS using the CoI model. If ARS is viewed within a framework, this study could also help policymakers have an idea of the feasibility of increasing access to education, and what types of support would be needed, now that education will be more spontaneous and 'hands-free'.

\section{References}

Atif, A., Jha, M., Richards, D., \& Bilgin, A. A. (2021). Artificial Intelligence (AI)-enabled remote learning and teaching using Pedagogical Conversational Agents and Learning Analytics. In Intelligent Systems and Learning Data Analytics in Online Education. Elsevier. https://doi.org/10.1016/B978-0-12-823410-5.000139, (pp 3-29)

Baumgartner, E., Bell, P., Brophy, S., Hoadley, C., Hsi, S., Joseph, D., Orrill, C., Puntambekar, S., Sandoval, W., \& Tabak, I. (2003). Design-Based Research: An Emerging Paradigm for Educational Inquiry. Educational Researcher, 32(1). 5-8. https://doi.org/10.3102/0013189X032001005

Cole, A. W., Anderson, C., Bunton, T., Cherney, M. R., Cronin Fisher, V., Draeger, J. . R., Featherston, M., Motel, L., Nicolini, K. M., Peck, B., \& Allen, M. (2017). Student Predisposition to Instructor Feedback and Perceptions of Teaching Presence Predict Motivation Toward Online Courses. Online Learning, 21(4). https://doi.org/10.24059/olj.v21i4.966

Collie, R. J. (2021). COVID-19 and Teachers' Somatic Burden, Stress, and Emotional Exhaustion: Examining the Role of Principal Leadership and Workplace Buoyancy. AERA Open, 7.

https://doi.org/10.1177/2332858420986187 
Cooper, T., \& Scriven, R. (2017). Communities of inquiry in curriculum approach to online learning: Strengths and limitations in context. Australasian Journal of Educational Technology, 33(4). https://doi.org/10.14742/ajet.3026

Deng, R., Benckendorff, P., \& Gannaway, D. (2020). Learner engagement in MOOCs: Scale development and validation. British Journal of Educational Technology, 51(1), 245-262. https://doi.org/10.1111/bjet.12810

Dhawan, S. (2020). Online Learning: A Panacea in the Time of COVID-19 Crisis. Journal of Educational Technology Systems, 49(1). 5-22 https://doi.org/10.1177/0047239520934018

Diliberti, M., \& Kaufman, J. (2020). Will This School Year Be Another Casualty of the Pandemic? Key Findings from the American Educator Panels Fall 2020 COVID-19 Surveys. RAND Corporation. https://doi.org/10.7249/RRA168-4

Dixson, M. D. (2015). Measuring Student Engagement in the Online Course: The Online Student Engagement Scale (OSE). Online Learning, 19(4). https://doi.org/10.24059/olj.v19i4.561

Edwards, B. I., \& Cheok, A. D. (2018). Why Not Robot Teachers: Artificial Intelligence for Addressing Teacher Shortage. Applied Artificial Intelligence, 32(4). 345-360 https://doi.org/10.1080/08839514.2018.1464286

Fast, E., \& Horvitz, E. (2017). Long-term trends in the public perception of artificial intelligence. AAAI'17: Proceedings of the Thirty-First AAAI Conference on Artificial Intelligence, 963-969.

García, E., \& Weiss, E. (2019). The teacher shortage is real, large and growing, and worse than we thought.

Garrison, D. R., Anderson, T., \& Archer, W. (1999). Critical Inquiry in a Text-Based Environment: Computer Conferencing in Higher Education. Internet and Higher Education, 2(2-3), 87-105. https://doi.org/10.1016/S1096-7516(00)00016-6

Goel, A. K., \& Joyner, D. A. (2015). An Experiment in Teaching Cognitive Systems Online. Computer Science.

Guan, C., Mou, J., \& Jiang, Z. (2020). Artificial intelligence innovation in education: A twenty-year data-driven historical analysis. International Journal of Innovation Studies, 4(4). 134-147 . https://doi.org/10.1016/j.ijis.2020.09.001

Hao, K. (2019). China has started a grand experiment in AI education. It could reshape how the world learns. MIT Technology Review.

Holmqvist, M. (2019). Lack of Qualified Teachers: A Global Challenge for Future Knowledge Development. In Teacher Education in the 21st Century. IntechOpen. https://doi.org/10.5772/intechopen.83417

Hou, M., \& Fidopiastis, C. (2017). A generic framework of intelligent adaptive learning systems: from learning effectiveness to training transfer. Theoretical Issues in Ergonomics Science, 18(2). 167-183. https://doi.org/10.1080/1463922X.2016.1166405

Jha, M., Richards, D., Porte, M., \& Atif, A. (2020, June). Work-in-Progress_-Virtual Agents in Teaching: A Study of Human Aspects. 2020 6th International Conference of the Immersive Learning Research Network (ILRN). (pp 259-262) https://doi.org/10.23919/iLRN47897.2020.9155122

Koh, Josiah. (2021, April). The Role of Non-Verbal Communication (NVC) in asynchronous online learning. FLANZ 2021: A Focus on Flexible Learning.

Liu, S., Gomez, J., Khan, B., \& Yen, C.-J. (2007). Toward learning oriented community college online course dropout framework. International Journal on E-Learning, 6(4). 519-542.

Maderer, J. (2016, May 9). Artificial intelligence course creates AI teaching assistant. ScienceDaily.

Maroco, J., Maroco, A. L., Campos, J. A. D. B., \& Fredricks, J. A. (2016). University student's engagement: development of the University Student Engagement Inventory (USEI). Psicologia: Reflexão e Crítica, 29(21). https://doi.org/10.1186/s41155-016-0042-8

Microsoft. (2020, January). QBot is here - Creating learning communities supporting inclusion and social learning in Teams for Education!

Popenici, S. A. D., \& Kerr, S. (2017). Exploring the impact of artificial intelligence on teaching and learning in higher education. Research and Practice in Technology Enhanced Learning, 12(22). https://doi.org/10.1186/s41039-017-0062-8

Reeves, T. (2006). Design research from a technology perspective. In J. Van den Akker, K. Gravemeijer, S. McKenney, \& N. Nieveen (Eds.), Educational Design Research (1st ed.). Routledge.

Rubin, B., Fernandes, R., \& Avgerinou, M. D. (2013). The effects of technology on the Community of Inquiry and satisfaction with online courses. The Internet and Higher Education, 17. 48-57 https://doi.org/10.1016/j.iheduc.2012.09.006

Ryu, S. (2020). The role of mixed methods in conducting design-based research. Educational Psychologist, 55(4). 232-243. https://doi.org/10.1080/00461520.2020.1794871

Shea, P., \& Bidjerano, T. (2010). Learning presence: Towards a theory of self-efficacy, self-regulation, and the development of a communities of inquiry in online and blended learning environments. Computers \& Education, 55(4). 1721-1731. https://doi.org/10.1016/j.compedu.2010.07.017

Siemens, G. (2020). As human beings, we cannot not learn. An interview with Professor George Siemens on connectivism, MOOCs and learning analytics. Journal of Applied Learning \& Teaching, 3(1).

https://doi.org/10.37074/jalt.2020.3.1.15 
Stein, S. (2018, January 8). Computers Can Have Artificial Intelligence, But They Aren’t Emotionally Intelligent.

Tiina, L., \& Ioana, G. (2016). An Evaluation Framework for Adaptive and Intelligent Tutoring Systems. ELearn: World Conference on E-Learning in Corporate, Government, Healthcare, and Higher Education, 1385-1390. https://www.learntechlib.org/primary/p/174082/

Underwood, J., \& Luckin, R. (2011). Themes and trends in AIED research, 2000 to 2010. A report for the UK's TLRP Technology Enhanced Learning - AIED Theme.

UNESCO. (2016). The World Needs Almost 69 Million New Teachers to Reach the 2030 Education Goals.

Wang, C. J., Ng, C. Y., \& Brook, R. H. (2020). Response to COVID-19 in Taiwan. JAMA, 323(14). 1341-1342. https://doi.org/10.1001/jama.2020.3151

Wenger, E. (1998). Communities of Practice: Learning, Meaning, and Identity. Cambridge University Press.

Whiteside, A. L. (2015). Introducing the Social Presence Model to Explore Online and Blended Learning Experiences. Online Learning, 19(2). https://doi.org/10.24059/olj.v19i2.453

Zawacki-Richter, O., Marín, V. I., Bond, M., \& Gouverneur, F. (2019). Systematic review of research on artificial intelligence applications in higher education - where are the educators? International Journal of Educational Technology in Higher Education 16(39). Springer Netherlands. https://doi.org/10.1186/s41239019-0171-0

Zhang, S., \& Liu, Q. (2019). Investigating the relationships among teachers' motivational beliefs, motivational regulation, and their learning engagement in online professional learning communities. Computers and Education, 134, 145-155. https://doi.org/10.1016/j.compedu.2019.02.013

Koh, J., Cowling, M., Jha, M., \& Sim, K.N. (2021). A proposal to measure the impact of automated response systems on meeting student learning outcomes. In Gregory, S., Warburton, S., \& Schier, M. (Eds.), Back to the Future-ASCILITE '21. Proceedings ASCILITE 2021 in Armidale (pp. 149-154).

https://doi.org/10.14742/ascilite2021.0120

Note: All published papers are refereed, having undergone a double-blind peer-review process.

The author(s) assign a Creative Commons by attribution licence enabling others to distribute, remix, tweak, and build upon their work, even commercially, as long as credit is given to the author(s) for the original creation.

(C) Koh, J., Cowling, M., Jha, M., \& Sim, K.N. 2021 